\title{
PEMBENTUKAN KARAKTER ANAK MELALUI KEGIATAN PASRAMAN \\ LASCARYA PARAMA SEVA DI DESA TIANYAR KECAMATAN KUBU KABUPATEN KARANGASEM
}

\author{
I Made Siryadana \\ siryadanamade@gmail.com \\ SMP Negeri 2 Kubu, Karangasem
}

\begin{abstract}
ABSTRAK
Memperhatikan perkembangan kepribadian anak-anak dan remaja dewasa ini, membuat para orang tua dan para pendidik harus mengubah pola pendidikan yang selama ini diterapkan. Pemerintah menanggapi keadaan ini dengan segera mencanangkan penanaman kembali nilai-nilai karakter. Pendidikan karakter ini tidak hanya dilakukan melalui pendidikan formal, melainkan juga dapat dilakukan melalui pendidikan nonformal, salah satunya adalah pasraman. Pasraman adalah sebuah kegiatan pendidikan nonformal yang berlandaskan Agama Hindu. Pasraman Lascarya Parama Seva di Desa Tianyar membentuk karakter peserta didik melalui kegiatan-kegiatan agama dan kebudayaan, seperti misalnya mesatua, sampai pada belajar Yoga. Proses implementasi pendidikan karakter melalui pasraman lebih banyak menyentuh domain afektif dan psikomotor dari pada domain kognitif. Bentuk pembelajarannya berlangsung secara klasikal, kelompok dan individu.
\end{abstract}

Kata Kunci : Pendidikan Karakter, Pasraman, Desa Tianyar 


\section{ABSTRACT}

Taking into account the personality development of children and adolescents today, parents and educators must change the pattern of education that has been applied so far. The government responded to this situation by immediately proclaiming the re-planting of character values. This character education is not only done through formal education, but can also be done through non-formal education, one of which is pasraman. Pasraman is a non-formal educational activity based on Hinduism. Pasraman Lascarya Parama Seva in Tianyar Village shapes the character of students through religious and cultural activities, such as mesatua, to learning Yoga. The process of implementing character education through pasraman touches more on the affective and psychomotor domains than the cognitive domain. The form of learning takes place classically, in groups and individually.

Key words: Character Education, Pasraman, Tianyar Village

\section{PENDAHULUAN}

Pendidikan dinilai sangat potensial dalam pembangunan manusia seutuhnya dan merupakan investasi kemanusiaan jangka panjang. Seluruh masyarakat merasa bangga atas prestasi beberapa sekolah unggul yang mampu mengantarkan anak-anak cerdas meraih prestasi tinggi dalam berbagai jenjang olimpiade (Rusmianta, 2008:5). Dalam Bhagawad Gita (IV: 33) dijelaskan bahwa "Pengetahuan sejati sebagai kurban (yajna) adalah lebih besar dari kurban (yajna) kebendaan yang manapun, wahai penakluk musuh (Paramtapa, Arjuna), sebab semua perbuatan tanpa kecuali akan mencapai puncaknya dalam pengetahuan rohani". Tetapi, sebagian kita prihatin terhadap beragam sisi gelap kondisi faktual pendidikan yang belum bebas dari kerapuhan moral dan etika, kekaburan orientasi nilai, serta kelemahan mutu.

Dalam literatur pendidikan, tercatat tiga pilar institusi yang berfungsi sangat pokok yaitu keluarga, sekolah dan masyarakat. Institusi keluarga merupakan pilar dasar yang paling dini untuk menkostruksi tempat, sistem nilai dan pembudayaan. Sekolah merupakan pilar utama untuk mengembangkan sains, teknologi, wawasan multidimensi dan kebudayaan. Masyarakat adalah pilar praktis bagi implementasi praktek, pengalaman dan pemberdayaan seperti dinyatakan oleh Swami Vivekananda (1991: 89, dalam Rusmianta, 2008 ) bahwa seluruh rahasia terletak dalam praktek. Tiada seseorang yang sesungguhnya diajari oleh orang lain, masing-masing orang harus mengajarkan dirinya sendiri.

Guru-guru di luar hanyalah memberi saran yang membangunkan guru- guru didalam untuk mengerti apa adanya hidup ini. Demikian juga halnya dalam Agama Hindu, masalah pendidikan mendapat perhatian yang khusus, karena melalui pendidikan Agama nantinya akan dapat membentuk pribadi manusia 
yang berbhudi pekerti yang luhur, sebagaimana dinyatakan oleh Swami Sathya Narayana (Titib, 2003, dalam Rusmianta, 2008: 89) bahwa tujuan pendidikan pada umumnya adalah "pembentukan karakter yang baik" (character building).

Dalam Undang-Undang Pendidikan No. 20 Taahun 2003 tentang Sistem Pendidikan Nasional sebagai pengganti Undang- Undang Sitem Pendidikan sebelumnya, pada pasal 1 ayat 1 menyatakan : pendidikan adalah usaha sadar dan terencana untuk mewujudkan suasana belajardan proses pembelajaran agar peserta didki secara aktif mengembangkan potensi dirinya untuk memiliki kekuatan spiritual keagamaan, pengendalian diri, kecerdasan, ahlak mulia, serta keteramilan yang diperlukan dirinya, masyarakat dan negara. Pada ayat 2 dinyatakan bahwa pendidikan nasional adalah pendidikan yang berdasarkan Pancasila dan Undang- undang Dasar Negara Republik Indonesia tahun 1945 yang berakar pada nilai- nilai agama, kebudayaan nasional Indonesia dan tanggap terhadap tuntutan jaman (Suarya, 2011: 34).

Pasraman sebagai sebuah lembaga pendidikan nonformal sekarang ini banyak dilaksanakan dimasing- masing desa adat dalam upaya memberikan pembinaan dan pendidikan Agama kepada anak anak sebagai generasi penerus bangsa. Karena pendidikan Agama adalah pendidikan yang memberikan pengetahuan dan membentuk sikap, kepribadian dan keterampilan peserta didik dalam mengamalkan ajaran Agamanya, yang dilaksanakan sekuarang- kuarangnya melalui mata pelajaran/ kuliah pada senmua jalur, jenjang dan jenis pendidikan (PP.RI. NO. 55, Tahun, pasal 1 ayat 1 dalam Suarya, 2011: 25).

Pendidikan non formal yang bernaung dibaah Yayasan berupaya mengusung kedalam kultur, ketinggian spiritual dan keterampilan praktikal hadir sebagai upaya penyeimbang pengembangan jati diri dan karakter bangsa. Eksistensi Yayasan makin memperoleh relivansi, apreseseasi dan pemberdayaan dalam konteks lokal, NKRI, dan Global. Secara istoris, model pendidikan pasraman dalam masyarakat Bali memiliki akar tradisi yang sangat tua dan lebih tua dibandingkan dengan model sekolah. Model pendidikan pasraman banyak mendapat inspirasi dari kearifan lokal diperkaya oleh efos Ramayana dan Mahabharata yang kemudian memperoleh bobot kontekstual terkait degan konsep Jnana Yadnya ,Tri Kaya Parisudha, serta Catur Asrama. Karakteristik pendidikan pasraman dikembangkan dalam basis komunitas adat, kompetensi praktikal, vibrasi natural, spirit kebersamaan, roh spiritual, dan wawasan kebudayaan. Pendidikan berlangsung dalam kurun waktu relatif pendek, jangkauan terbatas, namun bernasional dalam rajutan kearifan, makan dan disiplin. Arah dan prinsip yang juga ditanamkan adalah : (1.). Adanya keseimbangan substansi lokal, nasional, universal, sehingga tidak terjebak didalam panatisme sempit; (2) tumbuhnya keseimbangan doniman kognitif, apektif, dan motorik, sehingga terhindar dari verbalisma; dan (3) terjaminnya aktualisasi dan kontinuitas, sehingga terejawantahkan secara nyata dalam kehidupan sehari- hari. Pendidikan pasraman sangat berpotensi untuk membangkitkan jati diri, budhi pekerti, dan masyarakat susila. Wawasan 
kebudayaan yang perlu dibangun tidak hanya harus berorientasi pada masa lampau, namun yang lebih penting adalah pada keseimbangan dalam trasmisi keluhuran masa lampau realitas paktual masa kini dan peluang serta tantangan masa depan. Perspektif wawasan kebudayaan perlu dimaknai sebagai penguatan nilai luhur lokal, pengembangan nilai baru melaui keterbukaan Nasional, serta pemberdayaan individu dan kolektif dalam kompetensi global untuk harmoni, kesetaraan, serta kesejahteraan (Yanrus, 2008: 89).

Pasraman adalah institusi pendidikan yang memberikan pendidikan baik yang formal dan non formalakan tetapi memiliki basis Hindu. Hal ini juga sejalan dengan program Parisada Hindu Dharma Indonesia (PHDI) dalam bidang penerangan dan pendidikan, yaitu mengembangkan dan mendorong pembangunan sarana pendidikan Agama Hindu berupa sekolah Minggu., pasraman, asram untuk pendidikan non formal dan sekolah tinggi atau institut untuk pendidikan formal, diberbagai wilayah Indonesia; ( Yanrus, 2008: 91).

Melalui pembelajaran dipasraman anak- anak diberikan pendidikan agama dan budaya agar kelak mereka mengetahui agama, adat istiadat dan budaya mereka. Melihat perkembangan perilaku anak- anak dan remaja Desa Tianyar yang cenderung telah melupakan sikap beradab, ramah, sopan, rajin, tekun dan sebagainya seperti diuraikan diatas. Dari pengamatan peneliti ditemukan bahwa anak- anak sudah berani melawan orang tua, kurang suka membuat upakara yadnya dalam skala kecil sekalipun. Kenyataan lainnya bahwa anak- anak tidak ada rasa cinta tanah air. Mereka senaknya membuang sampah tanpa peduli mereka berada dimana. Disamping itu anak- anak tidak kreatif, cenderung sesuatu yang gampang tanpa banyak berpikir.

Fenomena lainnya adalah bahwa anak kurang memiliki rasa tanggung jawab, kurang disiplin, tidak mengembangkan rasa ingin tahu, tidak suka bekerja keras, kurang gemar membaca, kurang peduli linglungan dan sosial.

Untuk Desa Tianyar, Kecamatan Kubu, Kabupaten Karangasem ada sebuah pasraman yang bernaung dibawah Yayasan Lascarya Paramaseva yang berdiri sejak tahun 2011. Sampai saat ini pasraman ini masih aktif dan menampung 98 orang siswa dari berbagai Sekolah Formal dari tingkat TK, SD, dan SMP. Menurut keterangan ketua Yayasan Lascarya Paramaseva I Gede Novaldy Pratama Tukawiputra, A.Md. (wawancara tanggal 6 Juli 2018), menyebutkan alasan dilaksanakannya kegiatan pasraman itu adalah; bahwa desa Tianyar dipandang rawan dari gempuran adat, budaya dan Agama terkait era Globalisasi yang penuh keterbukaan ini, termasuk didalamnya menghindari terkikisnya karakter anak-anak dan remaja di desa Tianyar khususnya. Mengenai waktu pelaksanaan kegiatan Pasraman ini yaitu setelah pulang sekolah anak-anak yaitu pukul 15.00 sampai dengan 17.00. Wita. Sehubungan dengan itu, pasraman Lascarya Paramaseva di desa Tianyar sangat menarik untuk dikaji secara ilmiah sebagai salah satu aspek pendidikan non formal. 


\section{PEMBAHASAN}

\subsection{Pentingnya Pendidikan Karakter Diimplementasikan Pada Pasraman Lascaraya Parama Seva Desa Tianyar}

Segala bentuk perubahan dan perkembangan selalu mennyajikan dua hal yang tidak terpisahkan, yauitu adanya dampak positif dan pengaruh negatif. Berkembangya desa Tianyar akibat adanya penggalian pasir dan batu atau galian golongan $\mathrm{C}$ berpengaruh besar terhadap sisi ekonomi masyarakat Tianyar. Dampak positif dari bergeliatnya perekonomian masyarakat Tianyar berdampak pada minat orang tua untuk memberikan peluang pendidikan yang setinggitingginya kepada anak- anaknya. Mulai ada minat generasi muda untuk merantau keluar desa dan bahkan banyak yang mengadu nasibnya di luar negeri menjadi TKI/ Tenaga Kerja Indonesia di kapal pesiar.

Banyak urban yang datang ke desa Tianyar untuk mencoba mencari penghidupan, sehingga muncul masalah tempat tinggal dan banyak ditemuai bedeng-bedeng, utamanya didekat pasar untuk tempat tinggal pendatang yang mana juga berdampak pada orang yang mempunyai lahan/tanah.

Banyak kost-kostan yang dibangun oleh orang yang bermodal untuk pendatang. Dengan pesatnya perkembangan di zaman sekarang ini, maka akan berpengaruh juga pada perkembangan anak-anak dan generasi muda Tianyar. Mudahnya mengakses imformasi dari ponsel dan hampir semua anak- anak sudah punya Hp, maka informasi seakan akan ada diujung jari mereka. Makah hal- hal yang belum pantas diakses kemungkinan karena ras ingin tahunya keras tidak tertutup kemungkinan akan diakses oleh anak-anaknya itu. Kondisi seperti ini memungkinkan para orang tua untuk berpikir mengarahkan anak- anaknya untuk tidak melakukan hal- hal yang bertentangan dengan karakter budaya kita.

Dari penuturan Jero Bendesa Adat Tianyar perkembangan anak- anak dan remaja sekarang ini di Tianyar khususnya adalah:

(1). Adanya gejala anak- anak yang besikap apatis/ cuek dengan tradisi daerah, dan cenderung menggampangkan masalah. Hal ini sangat merisaukan orang tua yang memiliki tanggung jawab mentransfer tradisi yang diwariskan leluhur. Tidak banyak anak- anak muda yang paham cara membuat katik sate, ngulat sengkui, dan bahkan tidak sedikit anak muda yang tidak bisa manggul/ metegenan.

(2). Anak- anak lebih suka menikmati sinetron dari pada menonton hal- hal yang ada kaitannya dengan budaya Hindu, seperti wayang, bondres, tari- tarian, geguritan dan sebagainya.

Demikianlah antara lain fenomena yang nampak berkembang dalam masyarakat umumnya, dan di desa Tianyar khususnya yang menjadi motifasi awal dimantapkannya kegiatan Pasraman. Tidak ada gunanya kita mengadakan penyuluhan agama kepada masyarakat, kalu pada dasarnya mereka tidak memahami agamanya sendiri. Kegiatan pasraman ini bermaksud mengisi jiwa dan raga anak dengan pembelajaran agama sejak dini. 
Dengan melibatkan siswa sejak SD sampai tingkat SLTP, berarti secara epektif mereka telah mendapatkan pendidikan agama hindu selama dipasraman. Harapanya dengan kegiatan pasraman, yang intensip akan dapat mengkondisikan mindset anak, agar kelak memahami betul tentang hidup, tujuan hidup, cara hidup, dan bagaimana berinteraksi dengan orang lain. Sehinga tujuan agama "moksartham jaghadhita ya ca iti dharma" dapat tercapai.

\subsection{Proses Implementasi Pendidikan Karakter Melalui Kegiatan Pasraman di Desa Tianyar}

Sebelum kegiatan pembelajaran dimulai, siswa dibiasakan untuk melakukan pembersihan lingkungan sekitar pasraman. Kegiatan pembiasaan ini dilakukan untuk menumbuhkan rasa peduli lingkungan, kemudian kegiatan diawali dengan Puja Trisandya dan doa secara bersama- sama. Puja Trisandya dan doa dipimpin oleh salah satu siswa dari peserta pasraman. Pembiasaan ini dimaksudkan agar siswa setiap akan melakukan sesuatu pekerjaan diawali dengan doa terlebih dahulu, agar kegiatan yang dilakukan berjalan lancar. Adapun materi-materi pembelajaran yang disajikan dalam kegiatan pasraman ini akan diuraikan sebagi berikut:

\section{Pembelajaran Budi Pekerti Melalui Mesatua}

Putu Suata, 1995 dalam pendahuluan materi Masatua, mengatakan bahwa, masatua/ bercerita merupakan salah satu dari bermacam- macam tradisi lisan dalam masyarakat sastra di Bali. Sementara menikmati pesona (kalangen/ ulangun), anak- anak sesungguhnya juga menikmati nilai yang terkandung dalam cerita. Secara singkat dapat dirumuskan bahwa, tujuan masatua dalam kegiatan pasraman untuk menanamkan nilai- nilai kebenaran dan kebajikan yang dilaksanakan sejalan dengan nilai keindahan. Kebenaran dan kebajikan sebagai kemampuan (kompetensi) Agama Hindu dan keindahan sebagai penampilan (performasi) Agama Hindu. Sejalan dengan proses pendakian rohani manusia melalui keindahan rasa, (rasa tattwa) menuju kebahagiaan rohani (bhaga tattwa). Jadi prinsipnya berupa proses pendakian dari rame/ ramya menuju sepi/ sunya.

Cerita yang disajikan dalam kegiatan bercerita hendaknya bersumber pada satra Hindu. Diantaranya Efos Ramayana dan Mahabharata. Diantara parwaparwa yang ada, rupaya Adi Parwa yang sarat dengan nilai Agama Hindu, dimana didalamnya unsure tattwa, susila dan upacara menyatu dalam sosok yang bulat dan utuh. Beberapa cerita yang termuat dalam materi pasraman yang telah dibukukan oleh Yayasan Widya Wrdhi Sabha adalah: Sang Uttangka, Bhagawan Rama Parasu, Sang Srutasena, Sang Janamejaya, Bhagawan Domya dan lain sebagainya. 
Pasraman Lascaraya Paramaseva menjadikan materi itu sebagai refrrensi sedangkan dalam pembelajaran, memilih cerita rakyat yang biasa diceritakan oleh orang tua- tua di Tianyar. Diantaranya, Pan Balang Tamak, Cupak Grantang, Mitologi Hari Raya Galungan dan lain sebagainya. Pembelajaran masatua sekaligus menjadi pembelajaran Budi Pekerti. Ternyata melalui kegiatan bercerita, semua nilai karakter dapat diimplementasikan. Keahlian tutor dalam membawakan cerita dapat mengekploitasi segala karakter dalam diri siswa. Dalam keadaan rasa emosi yang terbawa oleh alur cerita tutor dapat menekankan nilai- nilai karakter yang harus dikembangkan.

\section{Pelatihan Keterampilan Putra}

Sukayasa, 2002 dalam pendahuluan materi keterampilan putra mengatakan, pada masa pra remaja anak-anak sangat membutuhkan bereksperimen dalam mengembangkan potensinya. Intelegensia, bakat, minat dan keperibadian anak dalam perkembangannya sangat banyak dipengaruhi oleh kemampuan dan kesempatan dalam bereksperimen. Di Bali sejak masa lalu telah memiliki bentuk- bentuk permainan yang dapat menimbulkan dan mambangkitkan kgembiraan anak. Dalam beberapa permainan tersebut disisipi nilai- nilai moral yang sangat berguna. Dalam aktifitas tersebut anak dapat belajar sambil bermain. Melatih keterampilan seperti ngulat klatkat, membuat katik sate, membuat penjor, membuat klangsah, kisa dan sejenisnya adalah bentuk aktivitas keterampialan yang dapat mengembangkan nilai religious anak. Aktivitas ini sangat menarik, karena dapat dilaksanakan dalam susana kegembiraan, kekeluargaan dan bermain.

Pasraman Lascaraya Paramaseva Desa Tianyar memilih materi keterampilan putra diantaranya, ngulat klansah, ngulat klangsah, klatkat, mengupas nyuh daksina membuat katik sate sepit dan lain sebagainya. Nilai karakter yang dapat diimplementasikan melalui pembelajaran keterampilan putra adalah nilai religious, kerja keras, disiplin, rasa ingin tahu, cinta tanah air, peduli lingkunga social, mandiri, kreatif, tanggung jawab, bersahabat/ komunikatif, menghargai prestasi serta cinta damai. 


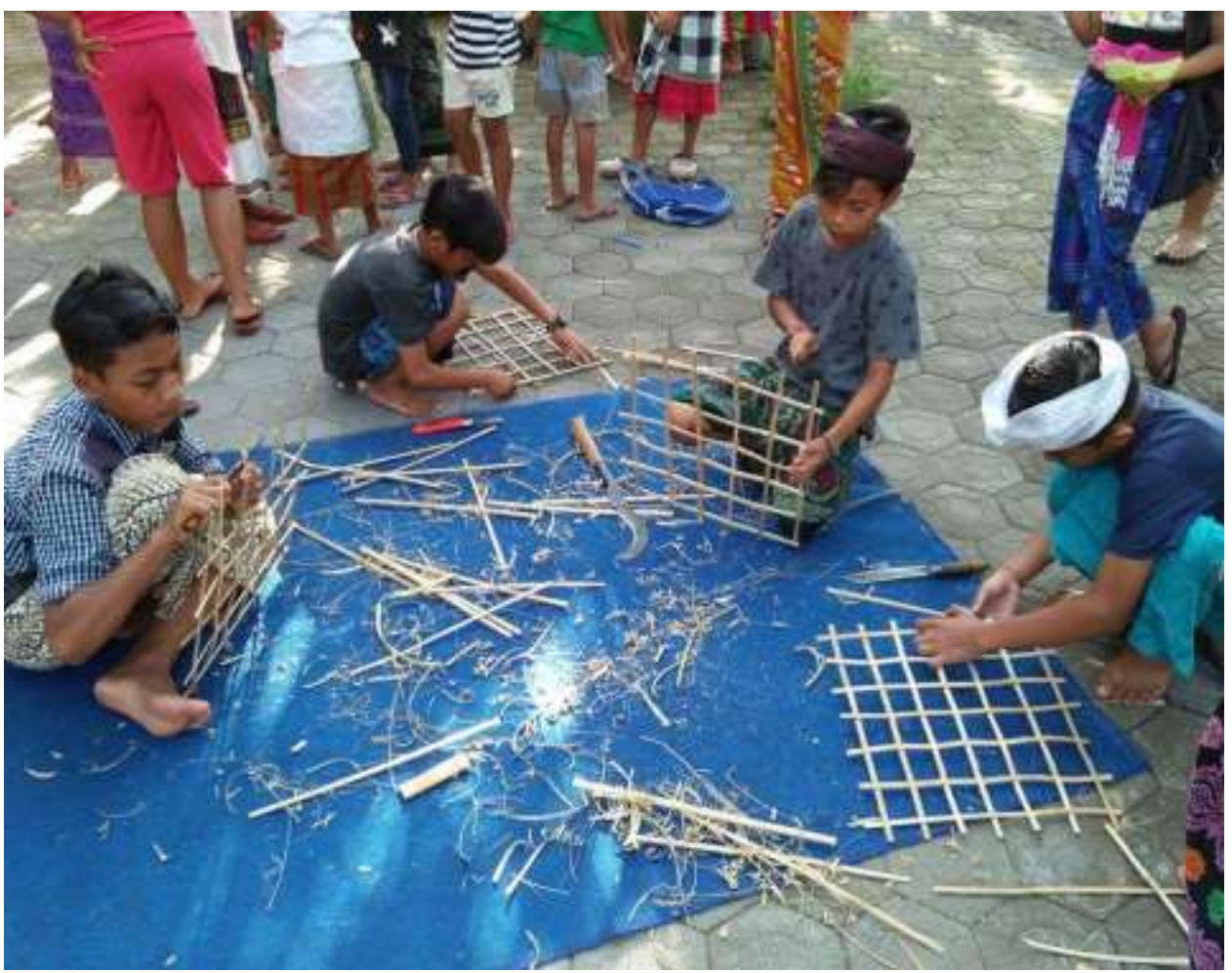

Pelatihan Keterampilan Putra

Dokumentasi: I Made Siryadana

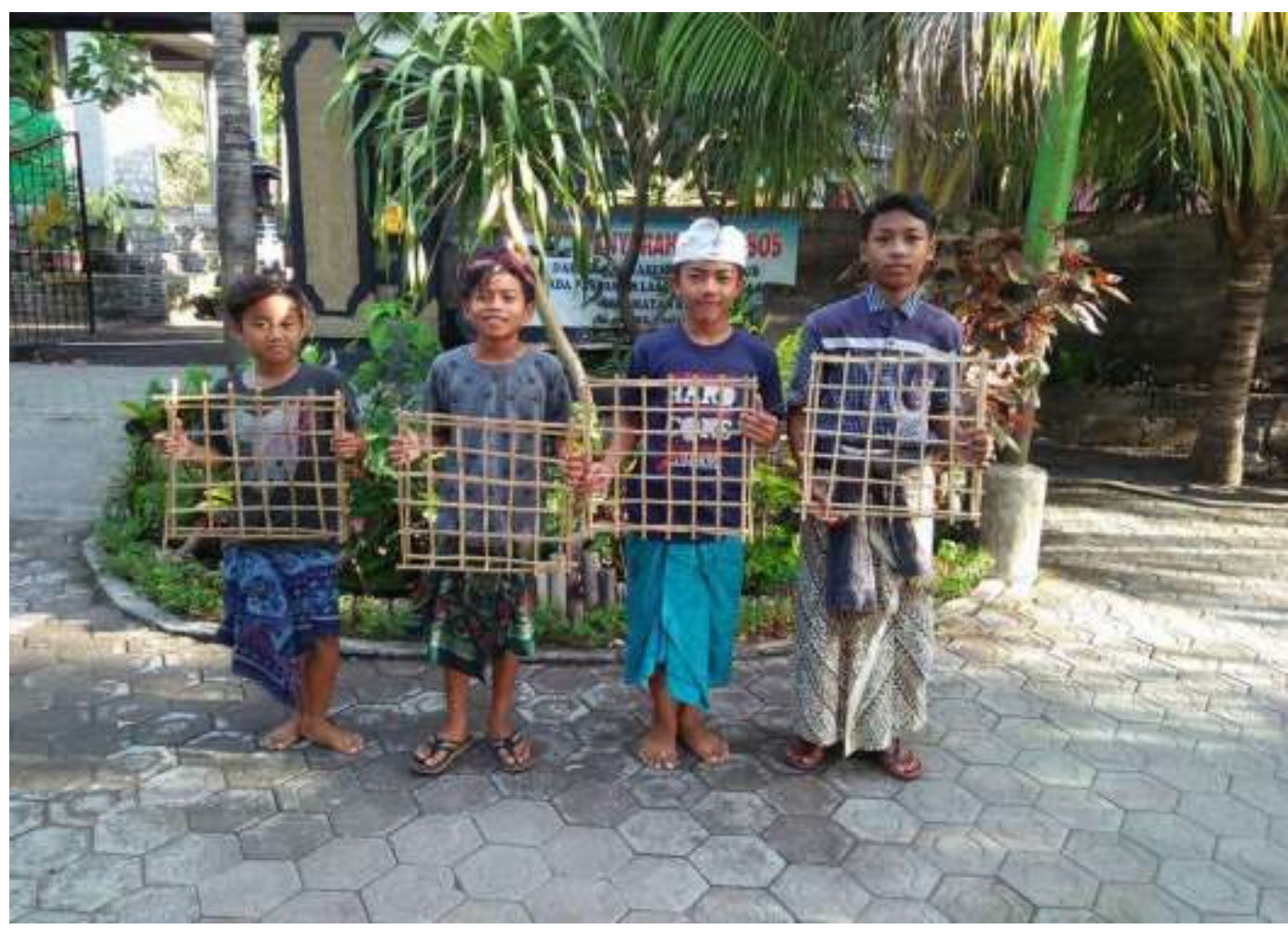

Pelatihan Keterampilan Putra

Dokumentasi: I Made Siryadana 


\section{Pelatihan Keterampilan Putri}

Umat Hindu di Bali menyatakan rasa bhaktinya kepada Tuhan/Ida Sang Hyang Widhi dengan bersembahyang yang senatiasa disertai dengan upakara berupa bebantenan. Proses membuat bebantenan inilah yang disebut dengan mejejahitan. Mejejahitan merupakan keterampilan dalam suatu pekerjaan tangan dengan mempergunakan sarana-sarana seperti janur, slepan, ron, ambu, rontal, sirih, plawa, daun pisang dan yang sejenisnya.

Mejejahitan pada dasarnya mengandung suatu konsep keindahan atau estetika, sangat menarik dipandang sehingga orang ingin belajar, sebab berbagai bentuk dapat diwujudkan. Semua jejahitan memakai ornament dengan teknis tetuasan dan reringgitan sehingga mengandung simbolis atau lambang suatu bentuk penyampaian rasa,maksud dan tujuan.

Fungsi jejahitan merupakan perwujudan sarana upakara, sebagai bentuk persembahan. Disamping itu jejahitan juga berfungsi sebagi dekorasi, yaitu hiasan yang bermakna simbolis misalnya tamiang, kolem, gatung- gatungan, ceniga/ lamak, dan sebagaianya. Dekorasi tersebut bermakna untuk menciptakan kemeriahan dan kesemarakan suatu ruang seprti hiasan paku pidpid, gebogan janur an sebagianya.

Adapun jenis jejahitan yang dapat dikemas sebagai praktek keterampilan anak- anak di Tianyar diantaranya, porosan, canag sari, canang meraka, kwangen, sodaan/ajuman, tipat kelanan, peras, pembersihan, daksina, segehan, pejatian. Sedangkan keterampialan remaja putri desa Tianyar yang dapat disajikan adalah, prayascita, biakaonan, segehan agaung. Ini berate jenis jejahitan yang harus dikusai adalah, taledan/ tamas, sampian peras, sampian pengambean, peneyeneng alit, sampian soda, tipat sida purna, kulit peras, serembeng daksina dan canag sari.

Pembelajaran keterampilan putra maupun putrid dilaksanakan diluar ruangan dengan cara duduk dilantai beralaskan tikar. Mulai dari proses pembuatannya kesucian upakara sudah dijaga. Anak- anak dilarang meletakan jejahitan sembarangan, jangan sampai melangkahi busung dan tidak boleh ada helai rambut yang menimpa jejahitan. Dianjurkan pula sedapat mengkin anakanak putrid mejejahitan dengan posisi kaki bersimpuh. Disela-sela mejejahitan inilah tutor menjelaskan unsur- unsur upakara seperti; apakah porosan itu?, Porosan sesungguhnya adalah symbol Dewa Tri Murti, yaitu Dewa Brahma dilambangkan dengan pinang, Dewa Wisnu dilambangkan dengan daun sirih,seta Dewa Siwa dilambangkan dengan kapur. Demikian pula dengan bentuk dari sampian yang cenderung makin keatas makin runcing, merupakan symbol dari penyatuan dengan Sang Hyang Widhi.

Dalam buku panduan materi pembelajaran sudah dicantumkan cara- cara masing-masing bentuk upakara. Dengan demikian tutor tidak mengalami kesulitan ketika melaksanakan pembelajaran. Di samping itu anak- anak yang sudah bisa membantu orang tuanya mejejahitan sangat mudah memahami pembelajaran. Tutor dapat memanpaatkan anak- anak seperti itu sebagai tutor 
sebaya dalam membantu tutor mengajarkan teman- temanya sehingga melancarkan proses pembelajaran.

Bagaimanapun besarnya upakara yang dibuat, anak-anak harus diingatkan bahwa usur pokok/ utama upakara itu adalah buah, bunga, daun dan air. Dalam kitab Bhagawad Githa Bab IX. 26 disajikan dalam bentuk sloka sebagai berikut : Pattram puspan phalam toyam

Yo me bhaktya prayacchati

Tad aham bhakti upartham

Asmani prayatatmanah

Artinya:

Siapapun yang dengan kesujudan mempersembahkan kepada-Ku daun, bunga, buah-buahan atau air, persembahan yang didasari oleh cinta dan keluar dari hati suci, Aku terima.

Sloka ini mengisyaratkan bahwa upakara yang kita persenbahkan kepada Ida Sang Hyang Widhi akan bernilai tinggi bukan karena besar dan mahal, apabila dipersembahkan dengan penuh rasa bhakti dan tulus iklas. Pemahaman ini wajib ditanamkan sejak dini agar yadnya yang dipersembahkan tidak sia- sia.

Nilai karakter yang dapat diimplementasikan lewat pembelajaran keterampilan putri, terutama adalah nilai religius dan disiplin. Didalam diri seseorang yang suka mejejahitan terdapat karakter disiplin dan rasa religious yang tinggi. Bagi oarang yang suka mejejahitan, beranggapan bahwa Ida Sang Hyang Widhi akan senang melihat semaraknya bebanten dan dekorasi tempat upacara. Dan hal seperti ini sangat membahagiakan hati orang yang bersangkutan. Kemudian sikap disiplin yang terbentuk dalam dirinya terwujud sikap tidak mau jejahitan yang dipersembahkan tidak lengkap dan lagi bahan yang digunakan harus segar. Nilai karakter yang lain adalah kerja keras. Orang yang suka mejejahitan mempertaruhkan kesenangannya itu walaupun harus bergadang, mejejahitan berhari- hari, duduk berlama-lama, bukan masalah baginya. Demikianlah ketinggian rasa religiousnya, yang dicapai dengan kerja keras, disiplin, mandiri, kreatif serta penuh tanggung jawab. 


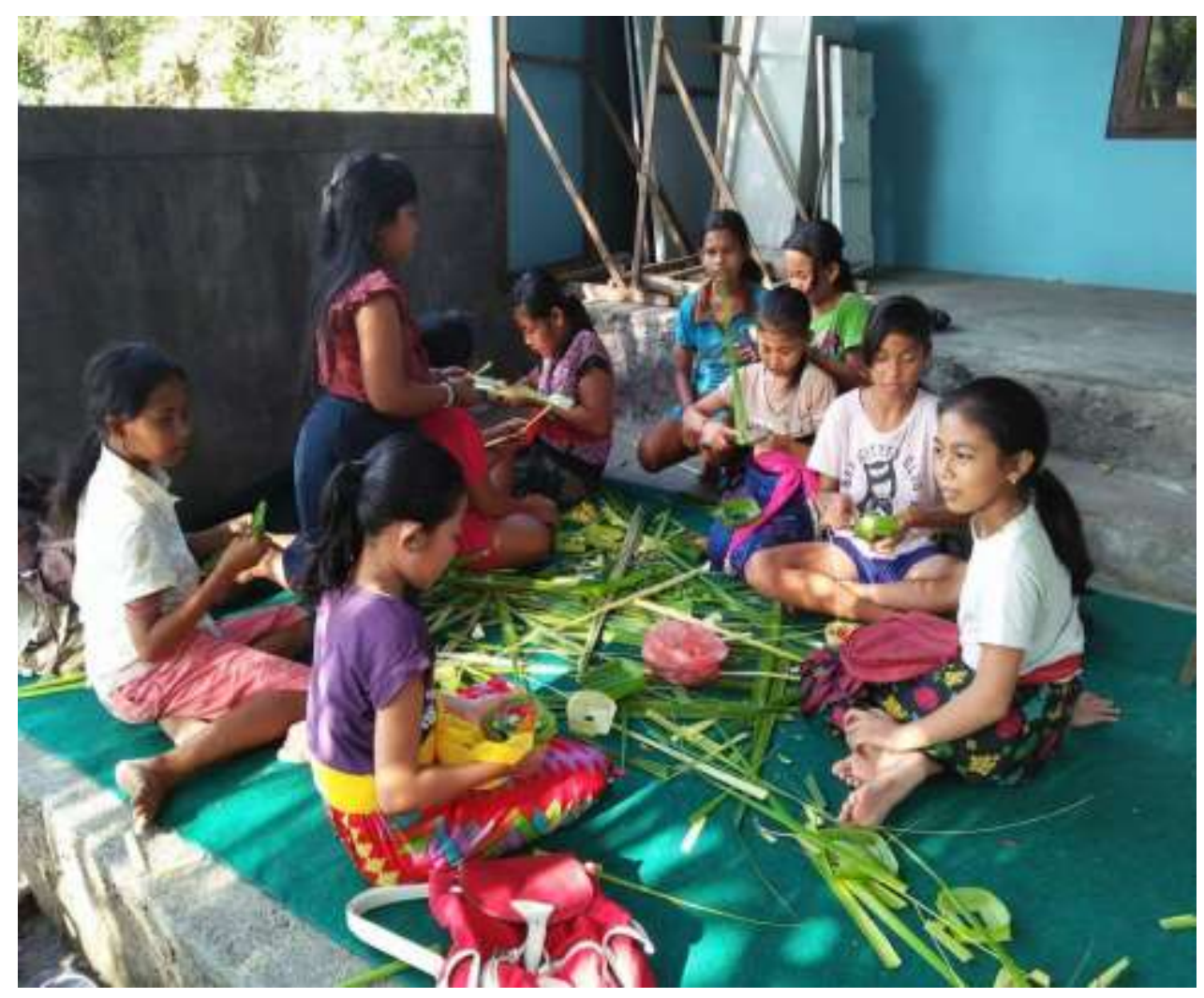

Pelatihan Keterampilan Putri

Dokumentasi: I Made Siryadana

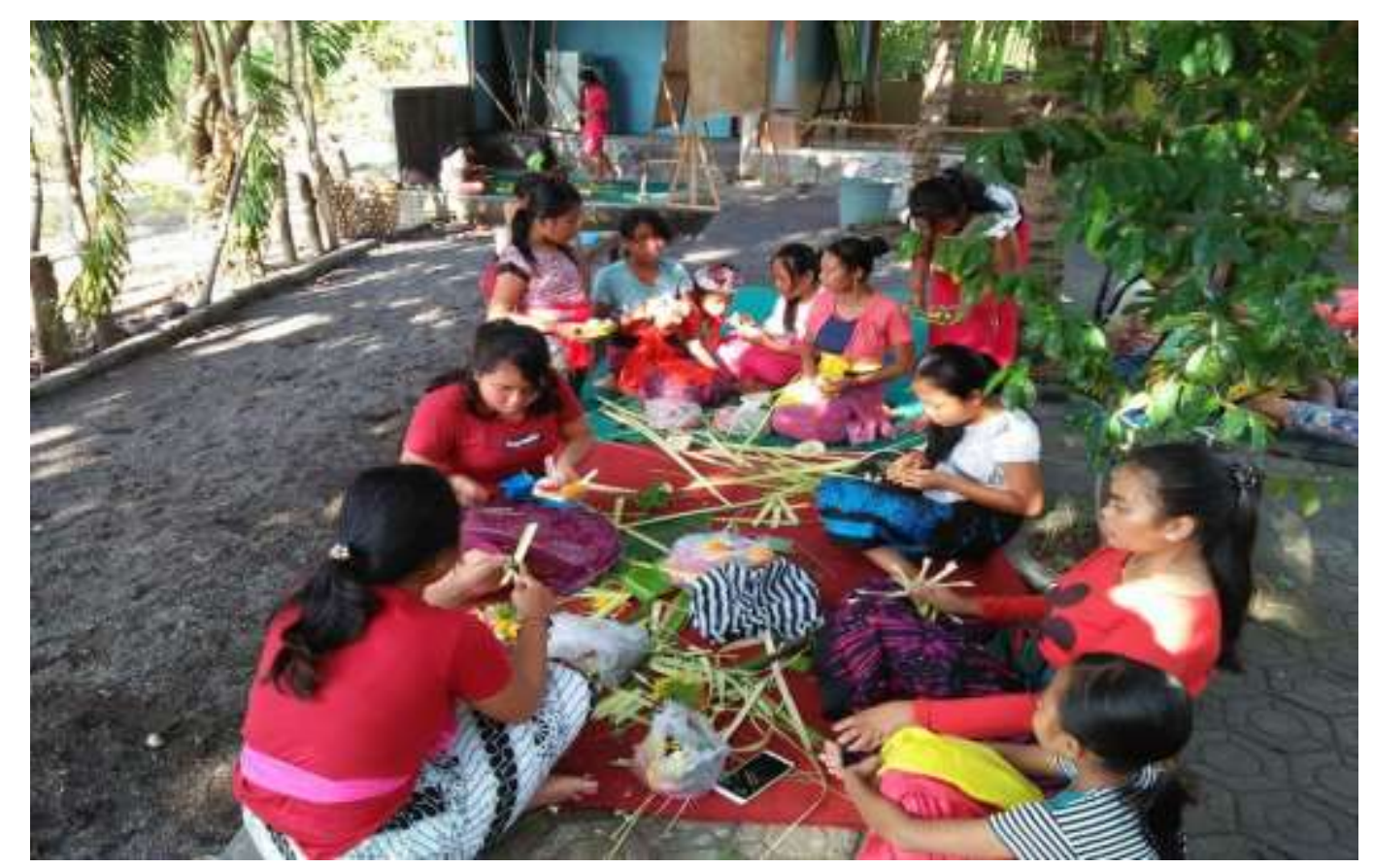

Pelatihan Keterampilan Putri

Dokumentasi: I Made Siryadana 


\section{Pelatihan Dharmagita}

Dharmagita adalah nyanyian dharma/kebaikan yang dinyanyikan setiap pelaksanaan upacara keagamaan Hindu. Dharmagita memiliki peranan penting dalam setiap pelaksanaan upacara. Dharmagita merupakan salah satu unsur dari panca gita yang terdiri dari; suara gambelan, suara kulkul, suara genta, suara puja dan suara kidung. Dharmagita juga sebagai curahan rasa bhakti dan sebagi alat konsentrasi pikiran menuju kesucian. Dharmagita dapat mengantarkan seseorang pada peningkatan kwalitas kerohanian. Mekidung sesungguhnya adalah latihan pranayama, dimana seperti diketahuai pranayama adalah pengaturan napas secara teratur sehingga dapat membersihkan pembuluh- pembuluh nadi. Itulah sebabnya orang yang suka mekidung memiliki pernapasan yang bagus.

Adapun materi pembelajaran Dharmagita yang diberikan untuk pasraman anak- anak maupun remaja adalah; warga sari, kidung warga sari, geguritan dan juga beberapa wirama seperti manda malon, swandewi, dan lain sebagainya. Berikut kutipan kidung yang disampaikan dalam pembelajaran di Pasraman.

\section{Kidung Kawitan Warga Sari}

Puwakaning angripta rum

Ning wana ukir

Kahadang labuh

Kartika panedhenging sari

Angayon tangguli ketur

Angringring jangga mure

Sukhania harja winangun

Winarna sari

Sampun riris

Samahahura ingoling tangi

Rumrumning puspa priyaka

Munggwing srengganing rejeng

\section{Kidung Wargasari}

Ida ratu saking luhur

Kawula nunas lugrane

Mangde sampun tiyang tandruh

Mangayat bhatara mangkin

Tityang ngaturang pejati

Canang sari muang daksina

Sami sampun puput

Pratingkahing saji 


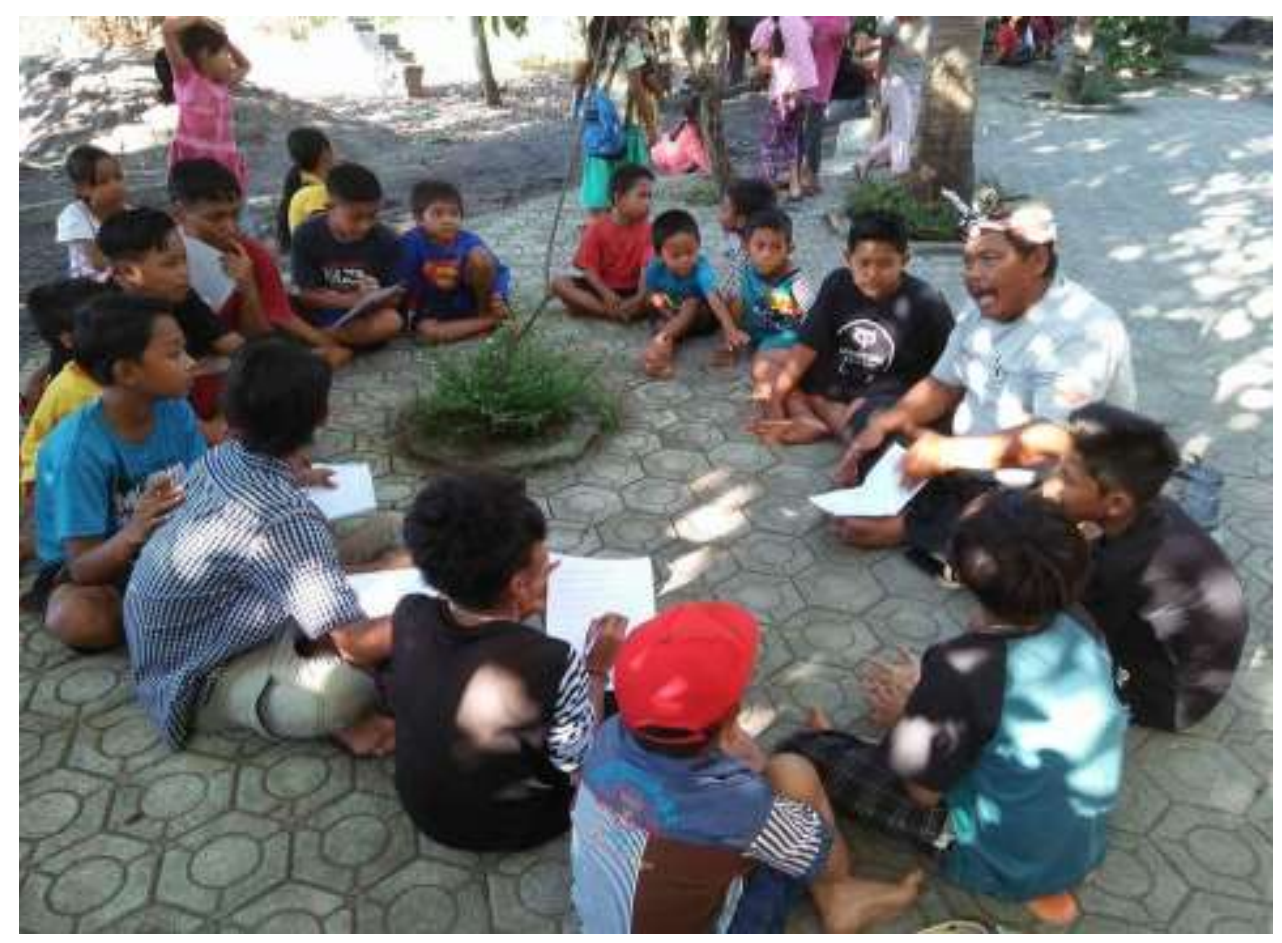

Pelatihan Darma Gita

Dokumentasi: I Made Siryadana

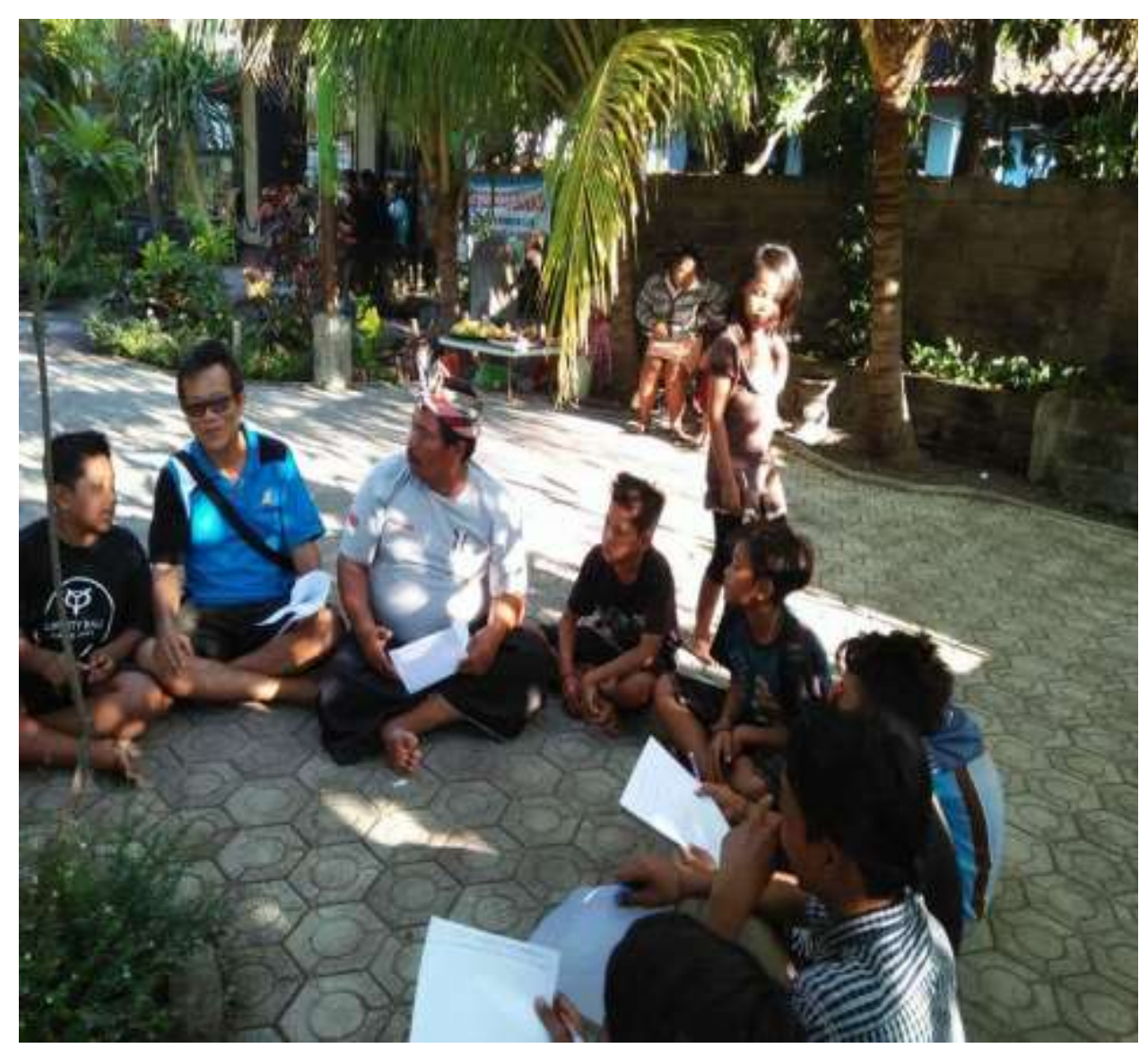

Pelatihan Darma Gita

Dokumentasi: I Made Siryadana 


\section{Pelatihan Nyastra}

Melalui materi pembelajaran nyastra siswa diarahkan untuk memahami bentuk-bentuk aksara Bali. Pentingnya mempelajari aksara Bali adalah karena banyak ajaran-ajaran Hindu yang tertuang didalam lontar, dimana lontar itu sendiri hanya boleh dibuka dengan bekal kunci aksara Bali. Kalau aksara Bali kita tidak kuasai, bagaimana kita hendak membaca lontar yang beraksara Bali, kalau kita tidak bisa dan paham aksara Bali serta tidak bisa membaca aksara Bali. Sedangkan dalam lontar itu berisi nilai-nilai luhur yang dituangkan oleh nenek moyang kita. Ini adalah alasan mendasar mengapa materi nyastra diselipkan dalam pembelajaran Pasraman.

Adapun materi pembelajaran nyastra di antaranya; pengenalan bentuk aksara Bali, pangangge suara, pangangge tengenan dan cara membacanya. Sedangkan untuk peserta pasraman remaja sudah diperkenalkan aksara swalalita. Misalnya saja wacana tentang efos Mahabharata, Ramayana yang sudah mempergunakan aksara sualalita. Di samping itu ketekunan nyastra dapat mengembangkan sikap disiplin, rasa ingin tahu, kerja keras, tanggung jawab, gemar membaca, mandiri, kreatif, menghargai prestasi, bersahabat/ komunikatif. Dan terakhir orang yang suka nyastra dapat mengembangkan rasa religious dan peduli sosial serta peduli lingkungan.

Menurut penuturan I Gede Konyolan (56 Th), nyastra adalah materi pembelajaran yang kurang diminati anak. Namun demikian para tutor tidak boleh putus asa untuk tetap tekun menuntun minat mereka terhadap aksara Bali. Warisan nenek moyang berupa lontar jangan sampai hancur tanpa pernah kita tahu apa isinya. Disinilah ketekunan dan kesabaran seorang tutor/guru dipertaruhkan.




Pelatihan Nyastra/ nyurat aksara Bali

Dokumentasi: I Made Siryadana

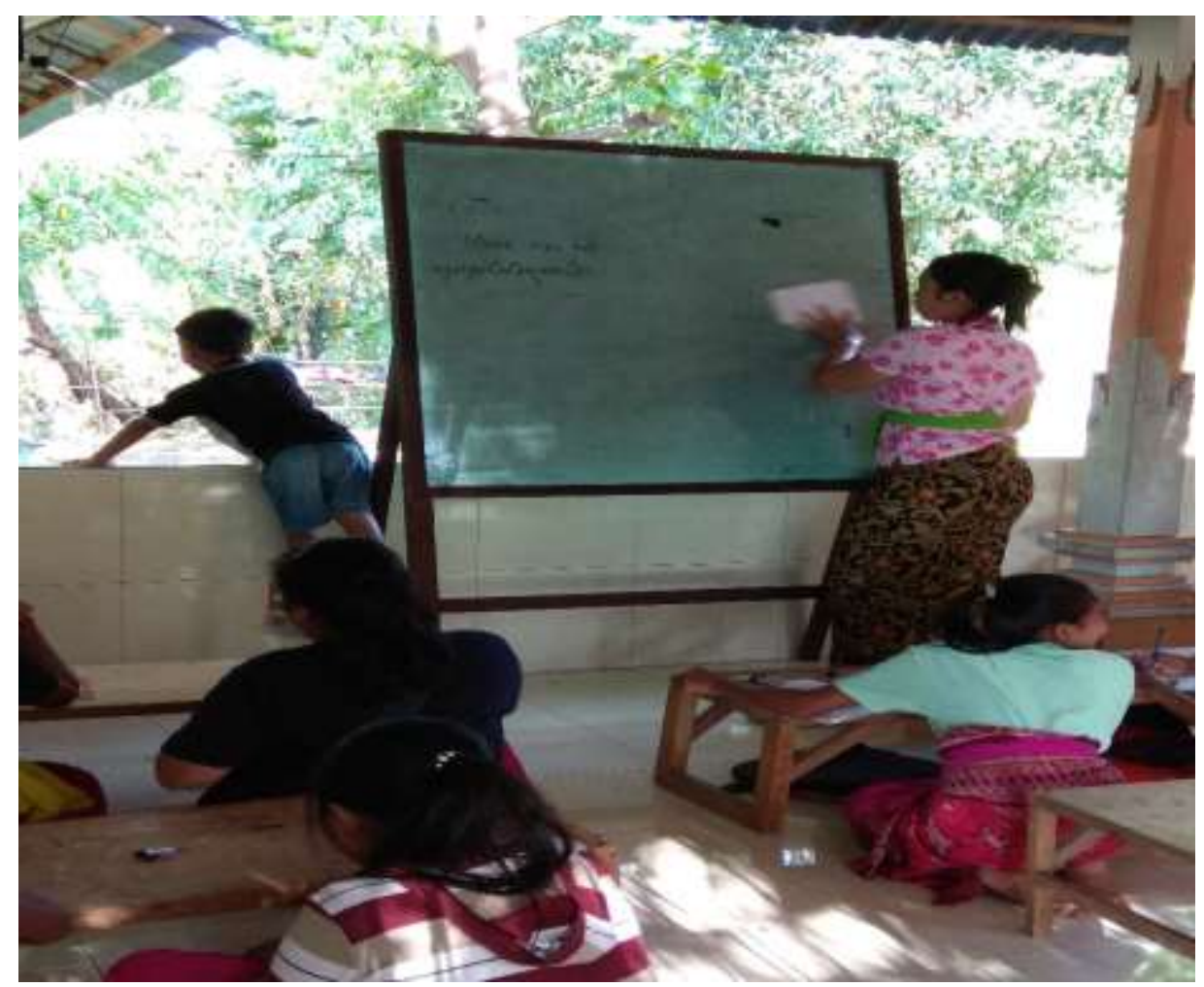

Pelatihan Nyastra/nyurat aksara Bali

Dokumentasi: I Made Siryadana

\section{Pelatihan Yoga Asanas}

Yoga asanas merupakan satu latihan fisik atau gerak tubuh yang menjadi cara untuk dapat meningkatkan kesehatan dan keseimbangan hidup, serta dapat memberikan manfaat dalam perkembangan fisik, mental dan kepribadian sepiritual. Kata yoga berasal dari kata Sansekerta yang diambil dari akar kata "yuj" yang berarti menyatukan diri dengan Tuhan. Pengertian lain dari yoga adalah penyatuan, yaitu penyatuan antara jiwa spiritual dengan jiwa universal. Dikatakan pula yoga adalah pembatasan pikiran- pikiran yang bergerak. Yoga juga terdapat dalam bahasa yunani yaitu " zygon" dan kata lainnya adalah "jugum".

Kamus istilah Agama Hindu ( 2006; 136-137) menjelaskan bahwa " yoga (s)" berarti hubungan: cara untuk mengendalikan gerak gerik pikiran untuk mengalami kenyataan jiwa yaitu bersatunya sang jiwa dengan jiwa yang maha agung ...yogas citta vrtti nirodhah (Yogasutra Patanjali,2). Yoga adalah pengendalian gerak gerik pikiran. Sedangkan Yogi (s) adalah orang yang telah berhasil dalam yoga. 
Adapun beberapa doa sebelum melakukan yoga asanas, seperti : Gayatri Mantram, Mrtyumjayamantra dan Mahamrtyummantram. Berikut disampaikan kutipan Mahamrtyummantram diambil dari doa sehari- hari menurut Hindu. ( 2006;32).

\title{
Om Tryambhakam yajamahe \\ Surgandhim pustivardanam \\ Urvarrukam iva bhadanat, \\ Mrtyor muksiya mamritat
}

\author{
Artinya: \\ Oh Hyang Widhi, hamba memujamu sebagai Rudra (treyabhaka) \\ Yang menyebarkan keharuman dan memperbanyak makanan \\ Hindarilah hamba dari keraguan \\ Bebaskanlah hamba dari penderitaan dan kematian
}

Memperhatikan kutipan doa divatas dapat dipahami bahwa Yoga Asanas adalah kegiatan penuh resiko yang apabila dilakukan tidak sesuai dengan urutan yang ada dapat menimbulkan cedera. Untuk itulah permohonan perlindungan kepada Tuhan selaku Dewa Rudra wajib dilakukan sebelum memulai Yoga Asanas. Divsamping itu juga mengingatkan siswa bahwa setiap kegiatan yang akan dilakukan hendaknya kita terlebih dahulu mohon ijin dan perlindungan kepada-NYA, agar tercapai sesuai harapan.

Beberapa jenis Yoga Asanas yang diajarkan dalam Pasraman adalah, Surya Namaskara, Pada Hastanasana, Trikonasana, Padmasana, Vajrasana, Halasana, Viparitakarani Mudra, Sethu Bandasana, Pascimotatanasana, Matsyasana, Tolagusana, Ardha Matsyendrasana, Savasana dan Sirshasana. Ada beberapa hal yang perlu dipersiapkan sebelum melakukan Yoga :

1. Yoga perlu dilakukan pada pagi hari saat matahari baru terbit.

2. Yoga perlu dilakukan pada saat perut sedang kosong. Lingkungan tempat melakukan Yoga hendaknyabersih dan udaranya segar.

3. Jangan makan tiga jam sebelum melakukan Yoga dan baru boleh makan setengah jam setelah selesai melakukan Yoga.

4. Pada saat melakukan Yoga, menarik dan mengeluarkan napas selalu melalui hidung. Latihan perlu dilakukan diats tikar atau karpet tipis yang tidak terlalu empuk.

5. Urutan yang dilakukan saat berlatih Yoga adalah pranayama, asana dan meditasi. Akan tetapi apabila sudah maju maka, meditasi dilakukan paling awal, sehingga berturut- turut: meditasi, pranayama dan asana.

6. Setelah selesai melakukan Yoga hendaknya berdoa agar sehat secara fisik, mental dan moral. Demikian pula berdoa ditunjukkan untuk semua manusia agar hidup bahagia dan tidak ada yang menderita.

Sepanjang pengamatan peneliti, kegiatan Yoga sangat disukai anak-anak maupun remaja. Mereka mengikuti setiap gerakan yang diinstruksikan oleh tutor 
tanpa ragu-ragu. Sudah banyak anak- anak yang bisa melakukan asanas dengan sempurna. Kelenturan tubuh mereka dan kemauan keras mereka menjadi salah satu alasan mereka dengan cepat dapat menguasai setiap asanas yang diajarkan. Hal ini tidak terlepas dari kemampuan instruktur dalam memandu kegiatan. Hanya dengan arahan kata-kata, anak-anak sudah dapat melakukan asanas dengan sempurna.

Untuk dapat menguasai satu gerakan asanas diperlukan ketekunan dalam berlatih. Ketekunan dan kesabaran serta usaha sungguh-sungguh, tidak mudah putus asa adalah wajah lain dari pada kerja keras. Di samping itu kedisiplinan, rasa ingin tahu, mandiri, kreatif, menghargai prestasi adalah motivasi lain yang mendorong seseorang untuk bisa menguasai suatu gerakan Yoga. Karena dalam melakukan gerakan Yoga diperlukan lingkungan yang bersih dan udara yang segar, maka mau tidak mau seseorang dituntut menciptakan lingkungan yang seperti itu. Ini adalah manifestasi dari nilai peduli lingkungan dan peduli social, cinta tanah air, serta cinta damai.

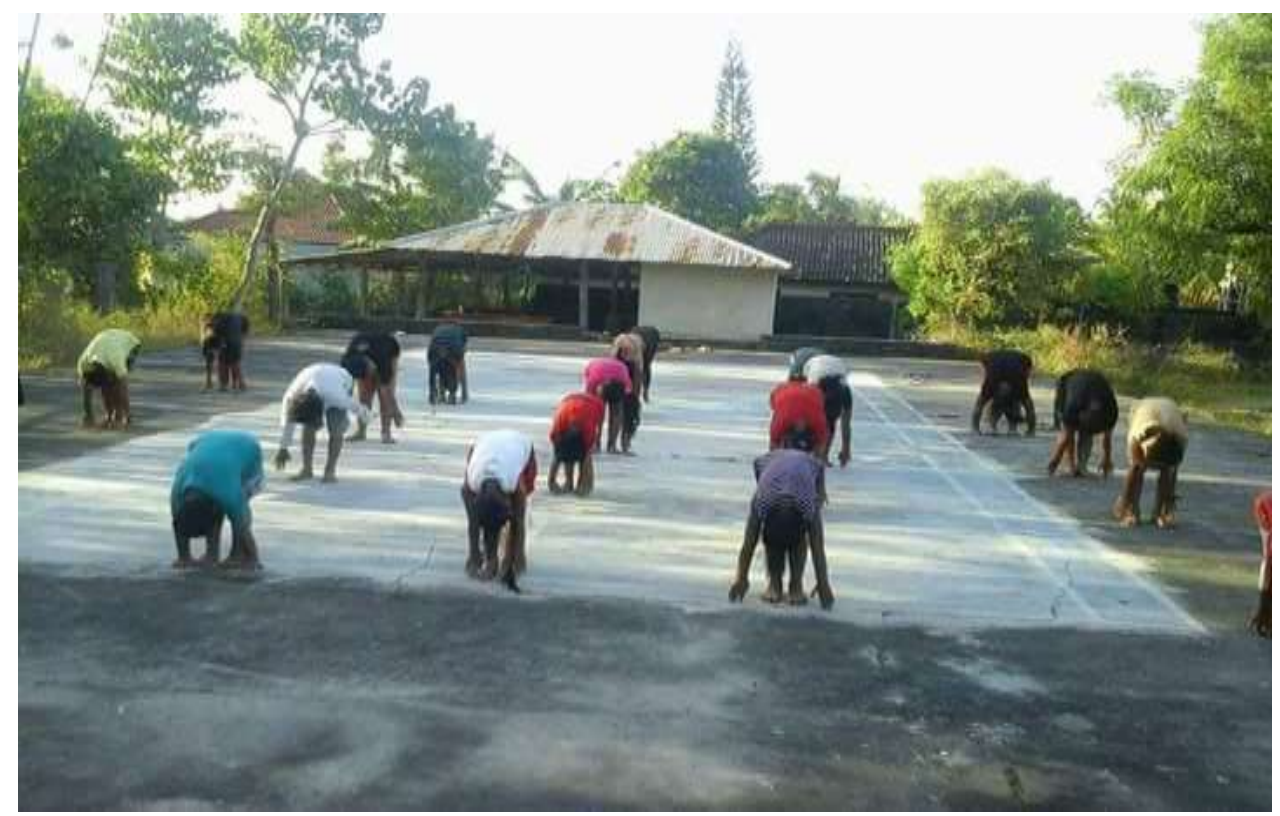

Pelatihan Yoga Asanas

Dokumentasi: I Made Siryadana

\section{PENUTUP}

Dari penelitian ini maka dapat dibuat simpulan sebagai berikut: perlunya implementasi pendidikan karakter melalui kegiatan pasraman Lascarya Paramaseva di Desa Tianyar, karena dipandang sangat rawan dari gempuran budaya luar akibat pesatnya perkembangan zaman, maka akan berpengaruh juga pada perkembangan anak-anak dan generasi muda Tianyar. Mudahnya mengakses informasi dari ponsel dan hampir semua anak- anak sudah punya Hp, maka informasi seakan-akan ada diujung jari mereka, hingga hal- hal yang belum pantas diakses kemungkinan karena rasa ingin tahunya keras tidak tertutup 
kemungkinan akan diakses oleh anak-anak. Kondisi seperti ini memungkinkan para orang tua untuk berpikir mengarahkan anak-anaknya untuk tidak melakukan hal-hal yang bertentangan dengan karakter budaya Hindu, maka dari itu Pasraman dipandang sebagai kegiatan yang paling tepat untuk pembinaan dini terhadap mental spiritual anak dan remaja Tianyar. Melalui Pasraman para tutor dapat menekankan betapa pentingnya implementasi pendidikan karakter anak dan remaja Desa Tianyar.

\section{DAFTAR PUSTAKA}

Baharuddin.H.dkk.2012. Teori Belajar dan Pembelajaran. Jakarta: AR-RUZ

Departemen Pendidikan Nasional.2003,Undang- undang RI No.20 tahun 2003 , tentang sistim pendidikan nasional

Departemen Pendidikan Nasional.2008, Kamus Besar Bahasa Indonesia,Jakarta, Balai Pustaka.

Doyo, I Wayan.2011.Peranan Guru Agama Hindu dalam Menumbuhkembangkan Karakter Siswa Sekolah Menengah Kejuruan (SMK) Pariwisata Yapparindo di Klungkung. Tesis.Program Magister Pendidikan Agama Hindu Pasca Sarjana UNHI;tidak dipublikasikan.

Hurlock, Elizabeth, B.TT. Psikologi Perkembangan. Terjemahan Istiwidayanti

Kemendiknas, 2011, Pedoman Pendidikan Pendidikan Karakter, Jakarta: Kemendiknas Balitbang Pusat Kurikulum dan Pembukuan.

Moenir, Sir Wiliems. 1993.A.Sanskrit - English Dictionary . Delhi; Motilal Banasidass Publiser Private Limited.

Pudja I Nyoman S.1996. Bhagavadgita. Jakarta: Hanuman Sakti.

Pemda Tk.I Bali.2006. Kamus Istilah Agama Hindu. Denpasar: Pemda Tk. I Bali Pusbukur,2011.Pengembangan Pendidikan Budaya Dan Karakter Bangsa.Jakarta;Gramedia

Rusmianta, I Wayan. 2008. Peran Pendidikan Pasraman Dalam Mengembangkan Wawasan Kebudayaan. ( akses tanggal 2 Juli 2018). Tersedia dalam URL: yanrus.blogspot.com/. 
Sanjaya,Wina.2011.Strategi Pembelajaran, Jakarta; Kencana Prenada Media.

Suarya, I Dewa Ketut.2011. Peranan Pasraman Dharma Santhi Dalam Meningkatkan Sradha Bhakti Anak-anak di Desa Adat Tuka. Tesis. Program Magister Pendidikan Agama Hindu Pasca Sarjana UNHI;tidak dipublikasikan.

Sugiyono.2011, Metode Penelitian Pendidikan. Bandung; Alfabeta.

Titib, I Made 2005. Pendidikan Agama Hindu Berwawasan Multikultural. Institut Hindu Darma Negeri Denpasar

Titib, I Made 2003. Menumbuhkembangkan Pendidikan Budhi Pekerti pada anak dalam perspektif Agama Hindu, Jakarta: Ganica Exsact

Uno, Hamzah B.2009.Teori Motivasi dan Pengukurannya. Jakarta : Bima Aksara.

Peraturan Menteri Pendidikan Nasional Nomor 41 Tahun 2007 Tentang Standar Proses Untuk Satuan Pendidikan Dasar Dan Menengah. Jakrta: Depdiknas.

Wina Sanjaya,Strategi Pembelajaran, Jakarta;Kencana Prenada Media Group

Wisnu Wardana, Cokorda Putra .2010. Pembelajaran Agama Hindu Pada Remaja Melalui Sistem Pasraman Di Desa Pakraman Sukawati Gianyar.Tesis. Program Magister Pendidikan Agama Hindu, Pasca Sarjana UNHI: tidak dipublikasikan. 